\begin{tabular}{|l|l|l|l|l|}
\hline Cuadernos de Investigación Geográfica & 2001 & $\mathbf{N}^{\circ} 27$ & pp. 137-146 & ISSN 0211-6820 \\
\hline
\end{tabular}

(c) Universidad de La Rioja

\title{
RUNOFF SIMULATION IN THE UPPER ODER CATCHMENT DURING THE FLOODING EVENT 1997 WITH A COUPLED ATMOSPHERIC / HYDROLOGICAL MODEL
}

\author{
H.-T. MENGELKAMP \\ J. SUTMOLLER \\ T. ZHAO
}

GKSS Research Center Geesthacht, D-21502 Geesthacht, Germany e-mail: mengelkamp@gkss.de

ABSTRACT: Two alternative modes of the land-surface scheme $S E W A B$ for the hydrological processes describe the two flood waves in the upper Oder catchment of the July 1997 flooding event with similar and reasonable accuracy. With the topographic index approach the peak value is slightly underestimated but correct in time while the reservoir concept shows a slight overestimation with a delay of one to two days. The inter polated observed and the simulated precipitation fields show remarkable differences in space and time. Consequently, the discharge also exhibits larger deviations.

RESUMEN: Dos versiones del modelo SEWAB describen las ondas de crecida durante la avenida del 7 de julio de 1997 en la cuenca del Oder. Mediante el uso del índice topográfico el pico de la avenida es ligeramente subestimado, aunque correcto en el tiempo, mientras que el concepto de embalse muestra una ligera sobreestimación con un retraso de uno o dos días. La precipitación observada y simulada muestra notables diferencias en el tiempo y en el espacio y, consiguientemente, el caudal también mues tra grandes desviaciones.

Key-words: Hydrological modelling, Flood event, Simulation, Topographic index, Oder River, Germany.

Palabras clave: Modelización hidrológica, Avenida, Simulación, ïndice topográfico, Río Oder, Alemania.

\section{Introduction}

In July 1997 two episodes of heavy and intense precipitation in the upper reaches of the Oder basin in the Czech Republic and in Poland caused the largest flood disaster in this region for decades. More than 100 casualties occured, vast land areas were flooded and hundreds of cities and villages were inundated. The upper reaches include the Oder tributaries originating in the Sudete Mountains and the Beskidy Mountains. Flood forecasting for this area is particularly difficult due to the complex terrain. If - as is com- 
monly the case - the hydrological model is driven by observed precipitation data, lack of representativeness of the locally measured rainfall rate and improper spatial interpolation methods may cause incorrect streamflow simulations. Moreover, use of observed data limits the warning period to the transport time of the water into and through the river channel system. Extending the forecast period for flooding events continues to be a challenge for atmospheric and hydrological models. Forecasting the spatial and temporal distribution of precipitation still comprises large uncertainties. Furthermore, the amplitude and timing of the flood wave depends on the parameterization of the runoff generation process and the translation of the effective precipitation into streamflow by horizontal transport processes.

In this study the land-surface scheme SEWAB (Surface Energy and Water Balance, Mengelkamp et al., 1988) is used to simulate the flood wave of the July 1997 flood event. Runoff generation and the water transport into the river system are parameterized through linear storages (standard version, SEWAB-STA) and by the topographic index approach (SEWAB-TOP). While SEWAB-STA needs 6 parameters to be calibrated this number is reduced to 1 for SEWAB-TOP. The transport through the river channel system is described by an impulse response function as the solution of the St. Venant equation (Lohmann et al., 1996). SEWAB-STA and SEWAB-TOP simulated hydrographs for the upper Oder are compared for the period April 1 to August 30, 1997. These simulations are forced by observations for calibration purposes.

In a second approach we aim at simulating the flood wave by a nested model approach providing the forcing data by a chain of numerical models. The land-surface model SEWAB is implemented into the non-hydrostatic mesoscale model GESIMA (Geesthacht Simulation Model of the Atmosphere, Eppel et al., 1995) to provide the lower boundary conditions. GESIMA itself is nested into the operational weather forecast model (Deutschland-Modell, DM) of the German Weather Service. This simulation is confined to the first 4 days of the intense precipitation episode from July $4-7$ which initiated the Oder flood. The surface water budget from this nested model run is compared to a SEWAB-TOP simulation with observed forcing data.

\section{Models and database}

\subsection{The land-surface scheme SEWAB and the routing scheme}

The one-dimensional, vertical land-surface scheme SEWAB solves the coupled system of the surface energy and water balance equations considering partly vegetated surfaces (Mengelkamp et a.l, 1999 ) and snow cover (Warrach et al., 2001). In the soil the heat diffusion equation and Richards-equation are solved for 6 layers. A detailed description of the hydrological components of SEWAB is given in Mengelkamp et al. $(2000,2001)$. Here we focus on the runoff generation process. 


\section{SEWAB - STA}

In its standard version SEWAB describes runoff as the outflow out of two reservoirs which are filled by Darcian flow from the lowest of 6 soil layers. One reservoir with a long response time represents the slow baseflow component while the reservoir with the fast response time contributes to direct runoff. The drainage flow from the bottom soil layer is partitioned into the fast and slow reservoir by a calibration factor between 0 and 1. Runoff R [ kg m-2 s-1] from the storages follows the concept of a linear reservoir:

$R=K_{\text {slow }} W_{\text {slow }} \rho w+K_{\text {fast }} W_{\text {fast }} \rho w$

Where $W_{\text {slow/fast }}[\mathrm{m}]$ is the height of the reservoir or the amount of water in the respective reservoir per surface unit. $k=\operatorname{In} 2 / T$ is the recession coefficient with the half-life decay time $\mathrm{T}$ for the slow and fast reservoir, respectively. The maximum height of the reservoir and the decay time serve as calibration parameters. $\rho w$ is the density of water.

A depth dependend saturation hydraulic conductivity after Beven and Kirkby (1979) accounts for a vertically varying pore size in the following form:

$\mathrm{Ks}=\mathrm{Knso} \exp (\mathrm{fz})$

with f varying between 1 and $13 \mathrm{~m}$ according to soil characteristics. Knso is the saturation hydraulic conductivity at the surface. $f$ serves as an additional calibration parameter which then are 6 altogether. Depth $\mathrm{z}$ is negative downwards.

\section{SEWAB - TOP}

As an alternative to the standard version the topographic index approach is implemented in SEWAB to simulate runoff generation. This concept explicitly makes use of orographic data in a quasi-statistical fashion (Stieglitz et al., 1997, Beven and Kirkby, 1979). Since only the statistical distribution of the topographic index is required rather then an explicit accounting of the orography this approach can easily be applied to large spatial scales. Since the concept of the topographic index is described elsewhere (Beven and Kirkby 1979, Stieglitz et al., 1997, Warrach et al. 2001) only a brief summary is given here. The topographic index approach is based on the following assumptions:

- The groundwater table is nearly parallel to the soil surface so that the local hydraulic gradient is approximately $\tan \beta$ where $\beta[\mathrm{rad}]$ is the local hill slope angle.

- The vertical profile of Kns is described by equ. 2

- The ground water table is recharged at a spatially uniform and steady rate with respect to the response timescale of the watershed.

With these approximations an analytic relation exists between the mean water table depth $\mathrm{z}$ and the local water table depth $\mathrm{Zx}$ at any location $\mathrm{x}$ in the watershed. This can be approximated as: 
$\mathrm{Zx}=\mathrm{Z}+\mathrm{f}-1[\ln (\mathrm{a} / \tan \beta) \mathrm{x}-l]$

with In $(a / \tan B)$ being defined as the topographic index $X$, the ratio of the upslope drainage area, a, to the local slope at that point, $\tan \beta$. The mean watershed value of In $(\mathrm{a} / \tan \beta)$ is $l$. (Sivapalan et $a l ., 1987$ ) yields the baseflow $\mathrm{Rb}[\mathrm{m} / \mathrm{s}]$ as

$\mathrm{Rb}=\mathrm{Knso} / \mathrm{fexp}(-l) \exp (\mathrm{fz})$

From knowledge of the mean ground water table $\mathrm{z}$ and the cumulative distribution of the topographic index $\mathrm{X}$ the saturated fraction of the watershed and the corresponding baseflow can be calculated. $\mathrm{X}$ is derived from high resolution digital elevation data. The calibration parameter of this approach is the parameter $f$ of equation (4) which describes the vertical profile of the saturation hydraulic conductivity according to equation (2).

The runoff generated by SEWAB in each grid box is transported through the river network by a routing scheme which describes both, the time runoff takes to reach the boundary of a grid box and the water transport in the river network (Lohmann et al. 1996). The first process is described by a simple unit hydrograph approach while the transport in the river is described by an impulse response function. The same setting of the horizontal transport scheme is used throughout this study.

\subsection{The atmospheric circulation models}

Alteratively to using observed synoptic data to force the land-surface scheme SEWAB, SEWAB is implemented into the non-hydrostatic mesoscale model GESIMA which itself is nested into the hydrostatic regional scale Deutschland-Modell (DM) of the German Weather Service (Schrodin, 1997). The dynamical equations of GESIMA are derived in Kapitza and Eppel (1992), physical parametrizations and test cases are described in Eppel et al. (1995) and Mengelkamp (1991/1999).

The model domain of DM encompasses Central Europe with a horizontal mesh size of $\sim \mathrm{X}=14 \mathrm{~km}$. Whith focus on the Oder flood event April 4-8, 1997 Keil et al. (1999) performed four model runs initialized at 00 UT every day with a simulation time of +30 hours. Six-hourly analyses were used as initial and boundary conditions. Only data of the periods $+6 \mathrm{~h}$ till $+30 \mathrm{~h}$ of these simulations are considered and provided as boundary conditions to GESIMA with a hourly time interval.

The model domain of GESIMA (Figure 1) encompasses the upper Oder catchment, an area of $116.84 \mathrm{~km} 2$, with a horizontal grid size of $\sim \mathrm{x}=4 \mathrm{~km}$. GESIMAis run with a time step of $\mathrm{t}=20 \mathrm{sec}$. The DM data were linearly interpolated onto the GESIMAgrid and according the GESIMA time steps. These data were processed for the whole GESIMA domain and for an external boundary. Data for the whole GESIMA domain are used to initialize the simulations at 00 UT every day for a simulation time of +30 hours according to the DM simulations. Wind speed, temperature and specific humidity were nudged every time step at three boundary grid points of the GESIMA domain. Data of 


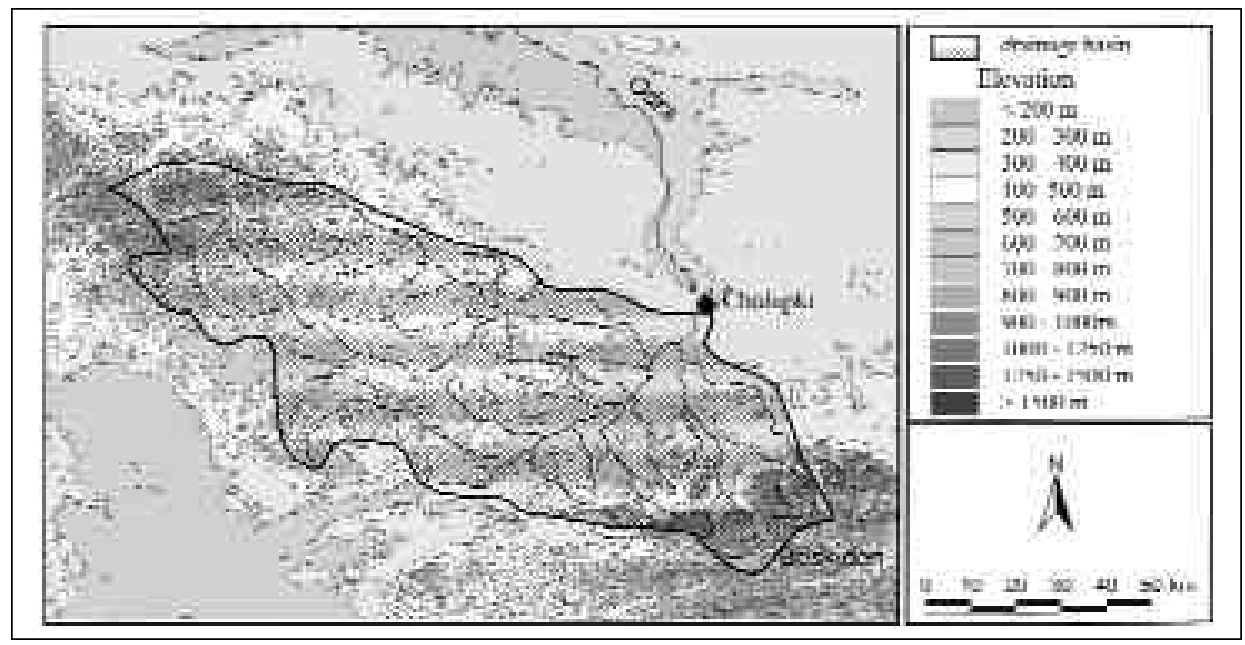

Figure 1: Orography of the Upper Oder catchment embedded in the simulation domain.

the simulation period +6 to +30 hours were considered to calculate daily sums of the surface water budget components. GESIMA simulations are performed for the period July 4-7 which includes the beginning of the first intense precipitation period which initiated the Oder flood.

\subsection{Data base and synoptic situation}

The upper Oder catchment encompasses a mountaineous area of $4600 \mathrm{~km} 2$ with heights up to $1300 \mathrm{~m}$ a.m.s.l in the northwesterly and southeasterly part. Its discharge is represented by the hydrograph of the gauging station Chalupki at $200 \mathrm{~m}$ height a.m.s.l. (Figure 1).

Digital elevation data with a horizontal resolution of $75 \mathrm{~m}$ are used to calculate the frequency distribution of the topographic index. They are aggregated on the $4 \times 4 \mathrm{~km} 2$ model grid for the SEWAB-TOPand GESIMAsimulations. Soil type is deduced from the FAO UNESCO soil map and the vegetation from the Corine land cover data.

Data from 10 synoptic stations are available with a 3-hourly interval as well as daily precipitation measurements at 13 climatotogical stations as forcing data for the off-line simulations with SEWAB. These data are spatially interpolated onto a $8 \times 8 \mathrm{~km} 2$ grid. i.e. the same forcing data are applied to 4 simulation grids, respectively. Daily discharge data at the gauging station Chalupki are used for calibration purposes.

Similar to other flooding events which occur almost regularly during summer in eastern-mid- european river basins, the 1997 Oder flood was initiated by a surface low which formed over nothern Italy and moved northeastward during July 6 (Figure 2). Warm and humid air masses were transported from the mediterranean to the eastern part of Central Europe and striked cooler air from the Baltic. Large scale lifting caused extrem precipi- 


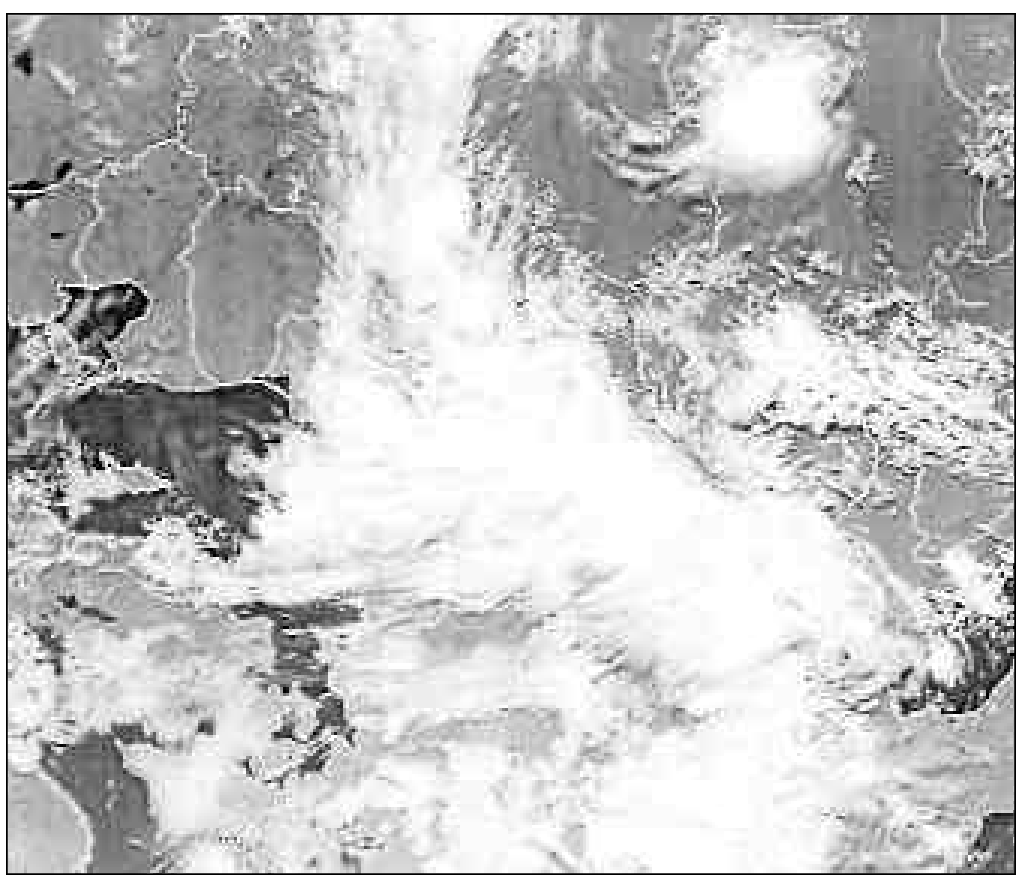

Figure 2: NOAA-12 image of July 6, 1997, courtsey by GKSS

tation over the Sudete mountains. The transport routes of precipitable water during this event are discussed by Keil et al., 1999.

\section{Comparison of SEWAB-STAand SEWAB-TOPfor the period April 1 to August 31}

The off-line simulations, i.e. forced by observations, for the period April to August 1997 are used for model calibration and to demonstrate the ability of SEWAB-TOP with only one calibration parameter to reproduce the flood wave similar to SEWAB-STA with 6 parameters. Figure 3 shows the hydrograph of both model runs and the observed discharge. During the three months period before the flood event the SEWAB-TOP simulated discharge somewhat languidly reacts on smaller precipitation events compared to SEWAB-STA. But the model is calibrated with focus on the flooding event and we accept smaller events to be simulated less accurately. The timing of SEWAB-TOP is excellent while SEWAB-STAis one to two days late. Concerning the amount of discharge SEWABTOP shows a slight overestimation contrary to SEWAB-STAfor the first flood wave.

\section{Simulation of the flooding period July 4-7 with the coupled DM-GESIMA- SEWAB model system}

The first four days (July 4-7) of the flooding period are simulated with the coupled model chain GESIMA-SEWAB forced by the DM model of the German weather service. 


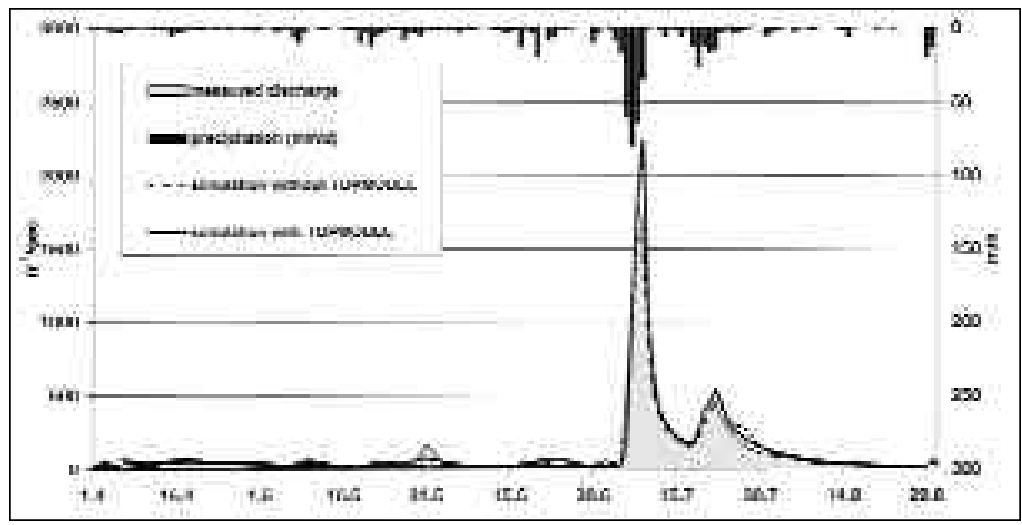

Figure 3: Observed and simulated hydrograph at the gauging station Chalupki for the period April 1 to August 31. 1997. For precipitation from the upper abscissa use the right ordinate.

This simulation is denoted ,GESIMA' and compared to the SEWAB-TOP simulation as described in section 3., in the following denoted ,SEWAB'. The areal distribution of precipitation, runoff and evapotranspiration is given in Figure 4, the daily sums of precipitation and discharge are listed in Table 1. Runoff is the excess water in each grid cell as calculated by the land-surface scheme; discharge is the runoff routed through the river channel system to the gauging station.

For the catchment area the precipitation as interpolated from observations amounts to $166 \mathrm{~mm}$ compared to $220 \mathrm{~mm}$ for the GESIMA simulation. The latter has pronounced maxima at higher elevations. The area mean evapotranspiration between the GESIMA(1 $\mathrm{mm})$ and SEWAB simulation $(9 \mathrm{~mm})$ differ remarkably. Consequently the area mean runoff from the GESIMAsimulation $(54 \mathrm{~mm})$ exceeds the SEWAB simulated runoff of $21 \mathrm{~mm}$. Because soil and vegetation characteristics and the parameterization scheme were the same for both simulations differences between the interpolated observed and the simulated forcing data can be the only cause. A detailed comparison of the observed and simulated atmospheric variables in view of the nesting technique, however, is out of the scope of this paper. The spatial distribution of runoff follows the precipitation pattern more closely for the GESIMA than for the SEWAB simulation.

Table l: Daily sums of precipitation and discharge as simulated by the «SEWAB» and «GESIMA» runs. In brackets is given the measured discharge at the gauging station Chalupki.

\begin{tabular}{|cccccc|}
\hline \multicolumn{2}{c}{ SEWAB } & \multicolumn{2}{c|}{ GESIMA } \\
\hline date & precipitation $(\mathrm{mm})$ & discharge $(\mathrm{m3})$ & & precipitation $(\mathrm{mm})$ & discharge $(\mathrm{m3})$ \\
4.7 & 8.9 & 22 & $(21)$ & 4.2 & 62 \\
5.7 & 17.0 & 27 & $(37)$ & 72.8 & 1258 \\
6.7 & 60.9 & 139 & $(492)$ & 41.3 & 758 \\
7.7 & 79.3 & 1066 & $(1149)$ & 102.5 & 998 \\
total & 166.1 & 1254 & $(1699)$ & 220.8 & 3076 \\
\hline
\end{tabular}



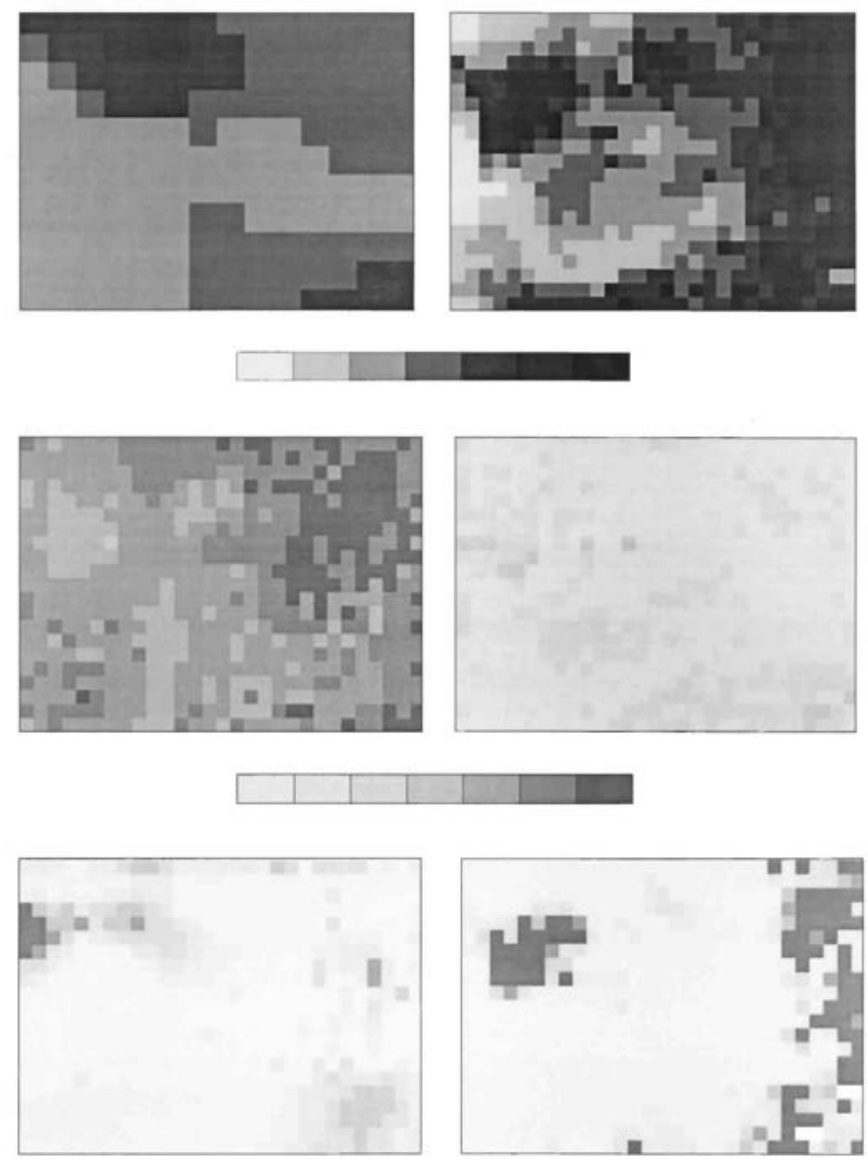

Figure 4: Sums of precipitation, evapotranspiration and runoff for the period June 4-7, 1997 from the off-line simulations (SEWAB, left hand side) and the nested approach (GESIMA, right hand side) for the simulation area depicted in Figure 1.

The daily sums of the measured discharge at the gauging station Chalupki gradually increase from the 4th to the 7th of July totalling to $1699 \mathrm{~m} 3$. The discharge from the SEWAB run is similar except the very low value on June 6. Discharge from the GESIMA simulation generally is too high with the maximum occuring too early. Obviously, this results from unrealistic precipitation simulations with the coupled model system. 


\section{Conclusions}

Two alternative modes of the land-surface scheme SEWAB for the hydrological processes, namely a concept based on linear reservoirs and the topographic index methodology, describe the two flood waves in the upper Oder catchment of the July 1997 flooding event with similar and reasonable accuracy. With the topographic index approach the peak value is slightly underestimated but correct in time while the reservoir concept shows a slight overestimation with a delay of one to two days. These simulations were forced by spatially interpolated observed synoptic data.

The topographic index approach is applied for the simulation of the flooding episode with a nested model chain, comprising the operational weather forecast model DM of the German Weather Service, the mesoscale model GESIMAnested therein and the land-surface scheme SEWAB. The interpolated observed and the simulated precipitation fields show remarkable differences in space and time. Consequently, the discharge also exhibits larger deviations. Compared to the observed discharge the timing and the amount of the discharge when calculated from observed forcing data follows the measurements more closely than the simulated discharge. The correct simulation of the spatial and temporal distribution of precipitation remains to be a challenge for atmospheric circulation models. It is even more difficult for a nested model chain. The uncertainty in precipitation simulations is the major source for incorrect discharge estimations.

\section{References}

Beven, K.J. and Kirkby, M.J. (1979). A physically based variable contributing area model of basin hydrology, Hydrol. Sci. J., 24: 43-69.

Eppel, D.P., Kapitza, H., Claussen, M., Jacob, D., Koch, W., Levkov, L., Mengelkamp, H.T. and Werrmann, N. (1995). The Non-Hydrostatic Mesoscale Model GESIMA, Part 1l: Parameterizations and Applications, Beitr. Phys. Atmosph., 68 (1): 15-41.

Kapitza, H. and Eppel, D. (1992). The non-hydrostatic mesoscale model GESIMA. Part 1: dynamical equations and tests, Beitr. Phys. Atmos., 65(2),129-146.

Keil, C., Volkert, H. and Majewski, D. (1999). The Oder flood in July 1997: Transport routes of precipitable water diagnosed with an operational forecast model, Geophys. Res. Letters, 26 (2): 235-238.

Lohmann, D., Nolte-Holube, R. and Raschke, E. (1996). A large scale horizontal routing model to be coupled to land surface parameterization schemes, Tellus, 48A: 708-721.

Mengelkamp, H.-T. (1991) Boundary layer structure over an inhomogeneous surface: Simulation with a non-hydrostatic mesoscale model, Bound. Layer Meteor., 57: 323 - 341.

Mengelkamp, H.-T., Warrach, K. and Raschke, E. (1999). SEWAB - a parameterization of the surface energy and water balance for atmospheric and hydrologic models, $A d v$. Water Res, 23 (2): 165-175.

Mengelkamp, H.-T. (1999: Wind climate simulation over complex terrain and wind turbine energy outputestimation, Theor.Appl. Climatol., 63: 129-139. 
Mengelkamp, H.-T., Warrach, K., Ruhe, C. and Raschke, E. (2000). Simulation of runoff and streamflow on local and regional scales, Meteor. Atmos. Phys., 76: 107-117.

Mengelkamp, H.-T., Kiely, G. and Warrach, K. (2001). Evaluation of hydrological processes added to an atmospheric land-surface scheme, Theor. Appl. Climatol, in print.

Schrodin, R. (ed.) (1997). Quarterly report of the operational NWP-models of the Deutscher Wetterdienst, available from DWD, D-63004 Offenbach, Germany.

Sivapalan, M., Beven, K. and Wood, E.F. (1987). On hydrologic similarity. 2, A scaled model of storm runoff production, Water Res. Res., 23: 2266-2278.

Stieglitz, M., Rind, D., Famiglietti, J. and Rosenzweig, C. (1997). An efficient approach to modeling the topographic control of surface hydrology for regional and global climate modeling, J. of Climate, 10: 118-137.

Warrach, K., Mengelkamp H.-T. ND Raschke, E. (2001). Treatment of frozen soil and snow cover in the land-surface model SEWAB, Theor. Appl., Climatol., 69: 23-37 